\title{
Optimisation of wire-cut EDM process parameter by Grey-based response surface methodology
}

\author{
Amit Kumar ${ }^{1} \cdot \operatorname{Tarun}_{\text {Soota }}{ }^{1} \cdot$ Jitendra Kumar ${ }^{1}$
}

Received: 6 March 2018/Accepted: 14 March 2018/Published online: 21 March 2018

(C) The Author(s) 2018

\begin{abstract}
Wire electric discharge machining (WEDM) is one of the advanced machining processes. Response surface methodology coupled with Grey relation analysis method has been proposed and used to optimise the machining parameters of WEDM. A face centred cubic design is used for conducting experiments on high speed steel (HSS) M2 grade workpiece material. The regression model of significant factors such as pulse-on time, pulse-off time, peak current, and wire feed is considered for optimising the responses variables material removal rate (MRR), surface roughness and Kerf width. The optimal condition of the machining parameter was obtained using the Grey relation grade. ANOVA is applied to determine significance of the input parameters for optimising the Grey relation grade.
\end{abstract}

Keywords Wire-cut EDM · Response surface methodology · Grey relation analysis · WEDM

$\begin{array}{ll}\text { Nomenclature } \\ \text { AE } & \text { Angular error } \\ \text { ANOVA } & \text { Analysis of variance } \\ \text { CCD } & \text { Central composite design } \\ \text { EDM } & \text { Electric discharge machining } \\ \text { GC } & \text { Gap current } \\ \text { GRA } & \text { Grey relational analysis } \\ \text { MRR } & \text { Material removal rate } \\ \text { MRSN } & \text { Multiple response signal-to noise ratio } \\ \text { MS } & \text { Machining speed } \\ \text { RSM } & \text { Response surface methodology } \\ \text { S/N } & \text { Signal-to-noise ratio } \\ \text { SG } & \text { Spark gap } \\ \text { SO } & \text { Single objective } \\ \text { SR } & \text { Surface roughness } \\ \text { WEDM } & \text { Wire electric discharge machining } \\ \text { WSN } & \text { Weighted signal-to-noise ratio } \\ T_{\mathrm{m}} & \text { Machining time (min) } \\ T_{\text {off }} & \text { Pulse-off time }(\mu \mathrm{s}) \\ T_{\text {on }} & \text { Pulse-on time }(\mu \mathrm{s}) \\ \max x_{i}^{(o)}(k) & \text { Maximum of } x_{i}^{(o)}(k) \\ \min x_{i}^{(o)}(k) & \text { Minimum of } x_{i}^{(o)}(k)\end{array}$

Jitendra Kumar

jitendrarajput1988@gmail.com

1 Bundelkhand Institute of Engineering and Technology, Jhansi, India

$\begin{array}{ll}W_{\mathrm{i}} & \text { Initial weight of workpiece material }(\mathrm{g}) \\ W_{\mathrm{f}} & \text { Final weight of workpiece material }(\mathrm{g}) \\ \epsilon_{i}(k) & \begin{array}{l}\text { Grey relational coefficient of the } i \text { th } \\ \text { experiment for the } k \text { th response }\end{array} \\ y_{i}^{*}(k) & \text { Normalised data } \\ \Gamma_{i} & \text { Grey related grade }\end{array}$

\section{Introduction}

Wire electric discharge machining (WEDM) process has opened a new swing in the manufacturing sector. Non-traditional machining processes changed the whole scenario of manufacturing industries. Traditional machining processes are rapidly replaced by non-traditional methods for achieving better production rates and quality. One of the successful methods is WEDM, which is based on the conventional electric discharge machining (EDM). The principle remains the same for WEDM as in conventional EDM, a thermoelectrical process. WEDM process involves the erosion effect by rapid repetitive and discrete spark discharges between the wire tool electrode and work piece in a liquid dielectric medium. Manufacturing the parts of high quality at high production efficiency is the main objective of WEDM process. Selecting the appropriate machining parameter for high quality product is very difficult. Much research is not found in the field of WEDM to find the optimum parameter; in the present research, GRA is used to find the response 
variable of WEDM. An attempt is made by Majhi et al. (2013) for the determination of the optimal process parameters material removal rate, surface roughness and tool wear rate for EDM process. Modelling and optimisation of WEDM were given by Kumar and Kumar (2013). To find the optimum surface roughness, they used to input parameters such as Time On, Time Off, Wire Speed and Wire Feed. Taguchi techniques have been used for optimisation of minimizing the SR. Due to multiple variables, an extremely trained operator with a modern WEDM is rarely to achieve the optimal performance. Pasam et al. (2010) conducted research to solve this problem to determine the relation among the responses and its parameter. The most important responses in WEDM are metal removal rate, workpiece's surface finish, and kerf width. Discharge current, pulse duration, pulse frequency, wire speed, wire tension, and dielectric flow rate are some of the machining parameters which affect the responses. The gap between the wire and work piece is also an important in wire EDM and it usually ranges from 0.02 to $0.075 \mathrm{~mm}$ given by Mahapatra and Patnaik (2007). Taguchi-based Grey relational analysis, to find the optimal process parameter setting for multi-matrix composite using molybdenum wire of $0.18 \mathrm{~mm}$ diameter, as electrode is applied by Lal et al. (2015). Similar technique for optimisation was used by Shivade and Shinde (2014) for D3 tool steel material. Nayak and Mahapatra (2016) applied an artificial neural network (ANN) model to determine the relationship between input parameters and performance characteristics for taper cutting of deep cryo-treated Inconel 718 with cryo-treated coated Bronco cut-W. In wire electrical discharge machining process $0.2 \mathrm{~mm}$ diameter wire electrode was used. Jaganathan et al. (2012) optimised the wire EDM parameter and responses MRR and surface finish for EN31 is done by Taguchi L27 orthogonal array (OA). Singha and Pradhan (2014) conducted experiment through Taguchi method and response surface methodology is applied to estimate the optimum machining condition within the experimental constraints. Varun and Venkaiah (2014) used an optimisation strategy by coupling Grey relational analysis (GRA) with genetic algorithm (GA) to optimise the response parameters. Experiments were conducted on EN353 work material to study the effects of input parameters. Zinc-coated copper wire with $0.25 \mathrm{~mm}$ diameter is used as an electrode. The response parameter such as material removal rate (MRR), the surface roughness (SR), and kerf width is observed. Saha and Mondal (2016) applied an optimisation technique combining Grey relational analysis with principal component analysis to identify the optimal combination of process parameters in WEDM for machining nanostructured hard facing materials. Sinha et al. (2015) used Taguchi method for single objective optimisation and then the signalto-noise $(\mathrm{S} / \mathrm{N})$ ratios obtained from Taguchi method have been further used in principal component analysis (PCA) for multi-objective optimisation. Huang and Liao (2003) applied Grey relational analyses with L18 mixed orthogonal array to determine the optimal selection of machining parameters for the wire electrical discharge machining process. Baig and Vankaiah (2001) applied Taguchi and Grey relation analysis to find the optimal parameter settings for WEDM for a nickel-based alloy.

This work investigates and optimizes the potential process parameters influencing the MRR, SR and kerf width while machining HSS M2 alloys using WEDM process. This work involves study of the relation between the various input process parameters like pulse-on time $\left(T_{\mathrm{on}}\right)$, pulse-off time $\left(T_{\text {off }}\right)$, pulse peak current (IP), and wire feed. The RSM method, a powerful experimental design tool, uses a simple, effective, and systematic approach for deriving the optimal machining parameters. Further, this approach requires minimum experimental cost and efficiently reduces the effect of the source of variation. An inexpensive and easy to operate methodology must be evolved to modify the machined surfaces as well as to maintain accuracy. RSM methodology by face centred design is used for conducting the design of experiments to optimise the experimental values for machining HSS M2 alloys by WEDM. A Grey relation approach is used to combine all the response in single response for optimisation to achieve single operating optimal condition for all the response MRR, SR and Kerf width.

\section{Experimentation detail}

Chemical composition of the material HSS-M2 is shown in Table 1. Two high speed steel plates of $100 \mathrm{~mm} \times 90$ $\mathrm{mm} \times 7.2 \mathrm{~mm}$ size are tempered in furnace to increase its hardness. It was hardened to $60 \mathrm{HRC}$. Then, with the help of WEDM it is sectioned into $20 \mathrm{~mm} \times 30 \mathrm{~mm}$ and it is weighed. Then, the sample is mounted on the EZEECUT NXG machine tool and specimens of $10 \mathrm{~mm} \times 10$ $\mathrm{mm} \times 7.2 \mathrm{~mm}$ size are cut by molybdenum wire of $0.18 \mathrm{~mm}$ diameter. Experimental setup of EZEECUT NXG machine is shown in Fig. 1.

The different levels of a factor consider for this study are depicted in Table 2. The fixed process parameter is voltage, molybdenum wire, HSS M2 work material, deionised water as dielectric fluid, wire tension, dielectric pressure, etc.

\section{Measurement of responses}

\section{Material removal rate}

MRR (metal removal rate) determined the economics of machining and rate of production. The material removal rate $(\mathrm{g} / \mathrm{min})$ is calculated by weight difference of the 
Table 1 Chemical composition of the material HSS-M2

Fig. 1 Schematic diagram of the WEDM EZEECUT NXG EN 3240 model

\begin{tabular}{llllllllllll}
\hline Constituent & $\mathrm{C}$ & $\mathrm{Mn}$ & $\mathrm{Si}$ & $\mathrm{S}$ & $\mathrm{P}$ & $\mathrm{Cr}$ & $\mathrm{V}$ & $\mathrm{Mo}$ & $\mathrm{W}$ & $\mathrm{Co}$ & $\mathrm{Cu}$ \\
\hline \% composition & 0.92 & 0.23 & 0.18 & 0.016 & 0.018 & 3.85 & 2.19 & 4.80 & 6.40 & 0.90 & 0.18 \\
\hline
\end{tabular}

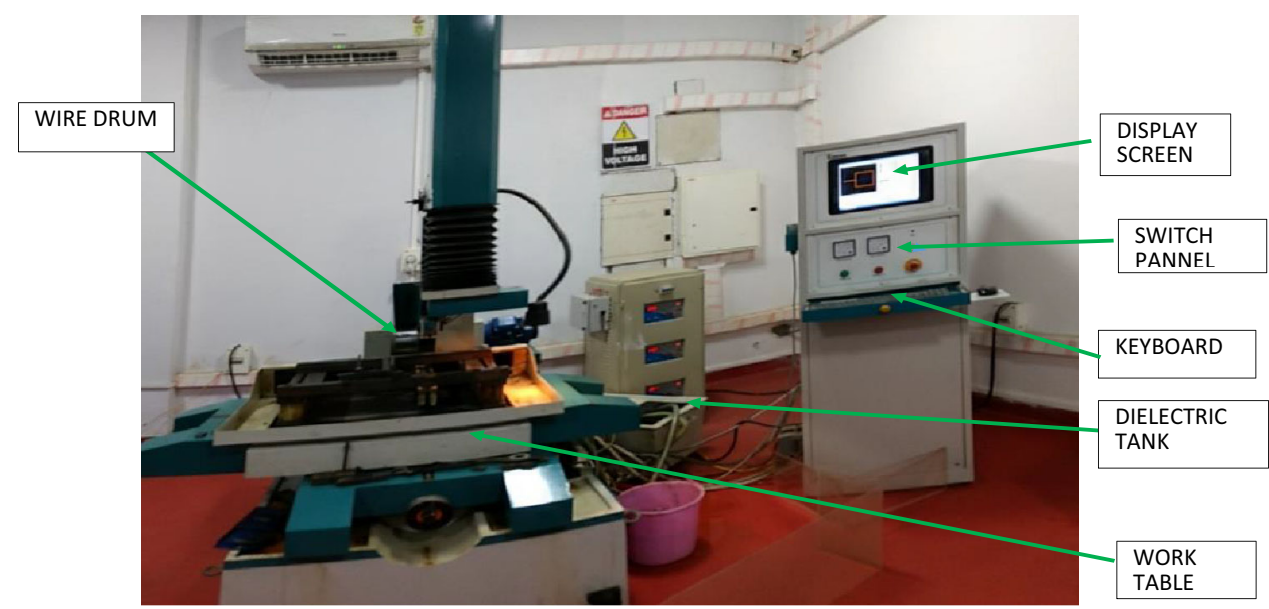

Table 2 Process parameters and their levels

\begin{tabular}{llrrr}
\hline Variable & Unit & \multicolumn{2}{c}{ Level } & \\
\cline { 3 - 5 } & & \multicolumn{1}{c}{-1} & \multicolumn{1}{c}{0} & 1 \\
\hline Pulse-on time, $T_{\text {on }}(A)$ & $\mu \mathrm{s}$ & 20 & 30 & 40 \\
Pulse-off time, $T_{\text {off }}(B)$ & $\mu \mathrm{s}$ & 5 & 10 & 15 \\
Current, IP $(C)$ & $\mathrm{A}$ & 1 & 2 & 3 \\
Wire feed, $W_{\mathrm{f}}(D)$ & $\mathrm{mm} / \mathrm{s}$ & 30 & 40 & 50 \\
\hline
\end{tabular}

specimens before and after machining. Mathematical formula used for measuring MRR for all experiments is given below:

$\operatorname{MRR}=\frac{W_{\mathrm{i}}-W_{\mathrm{f}}}{t}$

where $W_{\mathrm{i}}, W_{\mathrm{f}}$ is the initial and final weight of workpiece material $(\mathrm{g})$, respectively, and $t$ is the time period of machining in minutes.

\section{Surface roughness}

Roughness is a measure of the texture of a surface. It is measured $(\mu \mathrm{m})$ using Veeco Optical Profiler model NT 9080. Figure 2 shows a captured image of surface roughness of sample at parameter $20 \mu \mathrm{s}, 15 \mu \mathrm{m}, 1 \mathrm{~A}, 50 \mathrm{~mm} / \mathrm{s}$ of $T_{\text {on, }} T_{\text {off }}$, IP, and $W_{\mathrm{f}}$, respectively.

\section{Kerf width}

It is a measure of the amount of the material that is wasted during machining; it also affects the offset condition and thereby dimensional accuracy. For present experiments, kerf width has been measured using Mitutoyo Toolmaker's Microscope model TM 500. It is measured in mm. As shown in the Fig. 3.

Experimental results for four parameters in uncoded units with measurement of response (Material Removal Rate MRR, Surface roughness, Kerf width) are shown in Table 3.
Fig. 2 Surface roughness image at parameter at $20 \mu \mathrm{s}, 15 \mu \mathrm{m}$,

$1 \mathrm{~A}, 50 \mathrm{~mm} / \mathrm{s}\left(T_{\text {on }}, T_{\text {off }}, \mathrm{IP}, W_{\mathrm{f}}\right)$

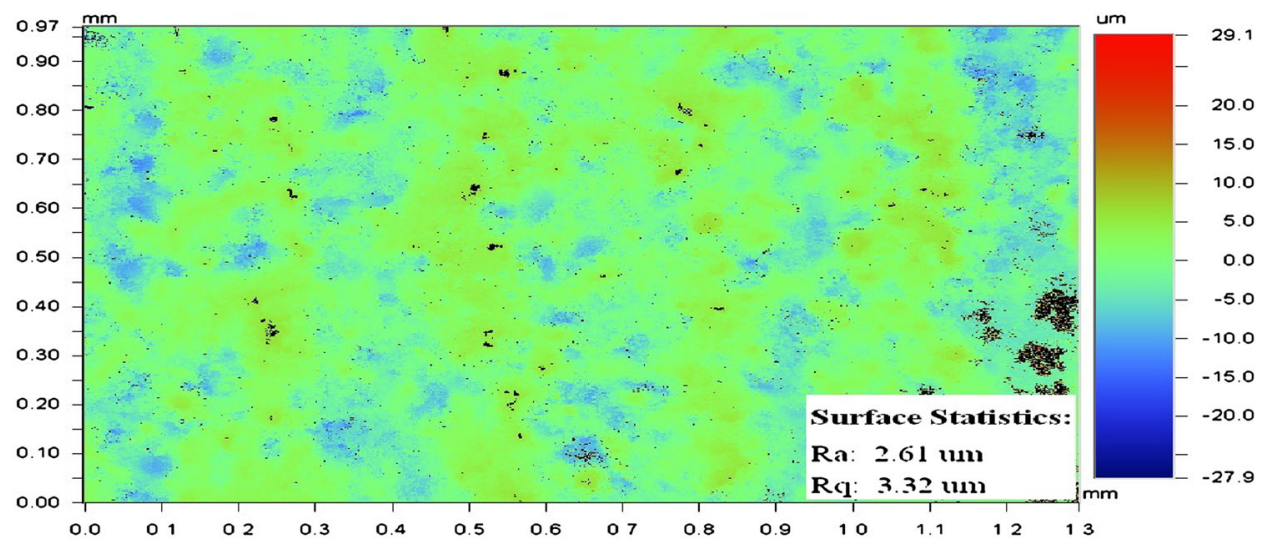




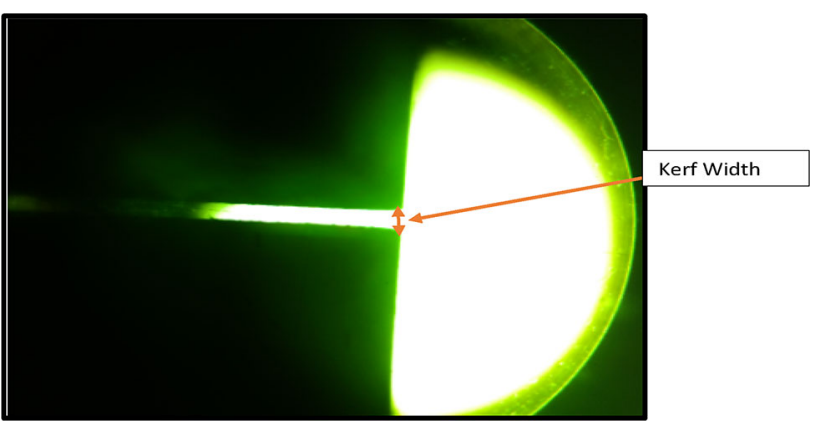

Fig. 3 Kerf width of sample image in Mitutoyo Toolmaker's Microscope model TM

\section{Grey relation analysis}

GRA is a decision-making method based on Grey system theory firstly technologically advanced by Deng (1982). In Grey theory, black means a system with insufficient information, while a white system represents complete information. However, the Grey relation is relative to partial information and is used to characterise the degree of relationship between the sequences so that the distance of two factors can be measured individually. When experiments are uncertain or if the experimental method cannot be performed accurately, Grey analysis contributes to compensating for the lack of statistical regression. Therefore, Grey relation analysis is an effective means of analysing the relationship between less-than-data sequences and can analyse many factors that can overcome the drawback of the statistical method by Pradhan (2013). In the Grey relational analysis, experimental data, that is the measured quality characteristics, are normally normalised in the range from 0 to 1 . This process is called Grey relational generation. Based on these data, the Grey relational coefficients are calculated to represent the correlation between the (best) ideal and the actual normalised experimental data. The overall Grey relational grade is

Table 3 Experimental results for four parameters in uncoded units

\begin{tabular}{|c|c|c|c|c|c|c|c|}
\hline \multirow[t]{2}{*}{ Run order } & \multicolumn{4}{|c|}{ Process parameter } & \multicolumn{3}{|l|}{ Responses } \\
\hline & $A\left(T_{\mathrm{on}}\right), \mu \mathrm{s}$ & $B\left(T_{\text {off }}\right), \mu \mathrm{s}$ & $C$ (IP), A & $D\left(W_{\mathrm{f}}\right), \mathrm{mm} / \mathrm{s}$ & MRR (g/min) & Surface roughness $(\mu \mathrm{m})$ & Kerf width (mm) \\
\hline 1 & 40 & 15 & 3 & 30 & 0.0349 & 3.77 & 0.22 \\
\hline 2 & 30 & 10 & 3 & 40 & 0.0314 & 4.48 & 0.22 \\
\hline 3 & 40 & 15 & 3 & 50 & 0.0263 & 3.66 & 0.23 \\
\hline 4 & 40 & 10 & 2 & 40 & 0.0357 & 4.85 & 0.25 \\
\hline 5 & 20 & 5 & 3 & 50 & 0.0253 & 3.96 & 0.215 \\
\hline 6 & 30 & 10 & 2 & 50 & 0.0268 & 4.23 & 0.2 \\
\hline 7 & 40 & 15 & 1 & 30 & 0.0095 & 3.55 & 0.24 \\
\hline 8 & 30 & 10 & 2 & 30 & 0.0383 & 4.5 & 0.225 \\
\hline 9 & 30 & 5 & 2 & 40 & 0.0298 & 5.5 & 0.23 \\
\hline 10 & 40 & 5 & 1 & 50 & 0.0163 & 5.82 & 0.225 \\
\hline 11 & 20 & 5 & 1 & 50 & 0.019 & 4.19 & 0.19 \\
\hline 12 & 20 & 15 & 3 & 30 & 0.0277 & 2.94 & 0.199 \\
\hline 13 & 20 & 5 & 3 & 30 & 0.028 & 4.4 & 0.22 \\
\hline 14 & 20 & 10 & 2 & 40 & 0.0276 & 3.04 & 0.19 \\
\hline 15 & 20 & 15 & 3 & 50 & 0.0208 & 2.32 & 0.19 \\
\hline 16 & 20 & 15 & 1 & 50 & 0.0088 & 2.61 & 0.19 \\
\hline 17 & 30 & 10 & 2 & 40 & 0.0309 & 4.42 & 0.21 \\
\hline 18 & 40 & 15 & 1 & 50 & 0.0141 & 3.3 & 0.21 \\
\hline 19 & 40 & 5 & 3 & 30 & 0.0529 & 6.55 & 0.24 \\
\hline 20 & 30 & 10 & 1 & 40 & 0.0201 & 4.35 & 0.205 \\
\hline 21 & 30 & 10 & 2 & 40 & 0.0304 & 4.38 & 0.2 \\
\hline 22 & 20 & 15 & 1 & 30 & 0.0073 & 2.78 & 0.195 \\
\hline 23 & 40 & 5 & 3 & 50 & 0.0283 & 6.38 & 0.225 \\
\hline 24 & 40 & 5 & 1 & 30 & 0.0101 & 5.9 & 0.24 \\
\hline 25 & 30 & 15 & 2 & 40 & 0.0278 & 3.27 & 0.19 \\
\hline 26 & 20 & 5 & 1 & 30 & 0.0064 & 4.21 & 0.22 \\
\hline
\end{tabular}


determined by averaging the Grey relational coefficients corresponding to the selected responses. The overall quality characteristics of the multiple response process depend on the calculated grey relational grade.

\section{Grey relational generation}

There are three different types of data normalisation according to the requirement of $\mathrm{LB}, \mathrm{HB}$, or NB criteria. MRR follows the HB criterion. So, the normalisation of original sequence of the response is done as follows:

$y_{i}^{*}(k)=\frac{y_{i}(k)-\min y_{\mathrm{i}}(\mathrm{k})}{\max y_{i}(k)-\min y_{i}(k)}$

where $y_{i}^{*}(k)$ is the normalised data, i.e. after Grey relational generation, $y_{i}(k)$ is the $k$ th response of the $i$ th experiment, $\min y_{i}(k)$ is the smallest value of $y_{i}(k)$ for the $k$ th response, and $\max y_{i}(k)$ is the largest value of $y_{i}(k)$ for the $k$ th response. Surface roughness and Kerf width follow the LB criterion. Accordingly, the normalisation of these responses is done as follows:

$$
y_{i}^{*}(k)=\frac{\max \mathrm{y}_{\mathrm{i}}(\mathrm{k})-\mathrm{y}_{\mathrm{i}}(\mathrm{k})}{\max y_{i}(k)-\min y_{i}(k)} .
$$

\section{Grey relational coefficient}

The Grey relational coefficient is given as:

$\epsilon_{i}(k)=\frac{\Delta_{\min }+\varpi \Delta_{\max }}{\Delta_{0 i}(k)+\varpi \Delta_{\max }}$

where $\epsilon_{i}(k)$ is the Grey relational coefficient of the ith experiment for the $k$ th response, $\Delta_{0 i}(k)=y_{0}^{*}(k)-y_{i}^{*}(k)$, i.e. absolute of the difference between $y_{0}^{*}(k)$ and $y_{i}^{*}(k)$, $y_{0}^{*}(k)$ is the ideal or reference sequence, $\Delta_{\max }=$ $\max _{i} \max _{k} y_{0}^{*}(k)-y_{i}^{*}(k)$ is the largest value of $\Delta_{0 i}$, and $\Delta_{\min }=\min _{i} \min _{k} y_{0}^{*}(k)-y_{i}^{*}(k)$ is the largest value of $\Delta_{0 i}$, and $\varpi\left(0^{k} \leq \varpi \leq 1\right)$ is the distinguishing coefficient and $\varpi=0.5$ is generally used.
Table 4 Grey relation coefficient

\begin{tabular}{|c|c|c|c|c|c|c|}
\hline \multirow[t]{2}{*}{ Experiment no. } & \multirow[t]{2}{*}{ MRR } & \multirow[t]{2}{*}{ SR } & \multirow[t]{2}{*}{ Kerf width } & \multicolumn{3}{|c|}{ Grey relation coefficient } \\
\hline & & & & $M R R \in_{i}(1)$ & $S R \in_{i}(2)$ & Kerf width $\in_{i}$ (3) \\
\hline 1 & 0.0349 & 3.77 & 0.22 & 0.5636 & 0.5933 & 0.5 \\
\hline 2 & 0.0314 & 4.48 & 0.22 & 0.5196 & 0.4947 & 0.5 \\
\hline 3 & 0.0263 & 3.66 & 0.23 & 0.4664 & 0.6122 & 0.4286 \\
\hline 4 & 0.0357 & 4.85 & 0.25 & 0.5748 & 0.4553 & 0.3333 \\
\hline 5 & 0.0253 & 3.96 & 0.215 & 0.4572 & 0.5632 & 0.5455 \\
\hline 6 & 0.0268 & 4.23 & 0.2 & 0.4711 & 0.5255 & 0.75 \\
\hline 7 & 0.0095 & 3.55 & 0.24 & 0.3488 & 0.6323 & 0.375 \\
\hline 8 & 0.0383 & 4.5 & 0.225 & 0.6143 & 0.4924 & 0.4615 \\
\hline 9 & 0.0298 & 5.5 & 0.23 & 0.5016 & 0.3994 & 0.4286 \\
\hline 10 & 0.0163 & 5.82 & 0.225 & 0.3885 & 0.3767 & 0.4615 \\
\hline 11 & 0.019 & 4.19 & 0.19 & 0.4068 & 0.5307 & 1 \\
\hline 12 & 0.0277 & 2.94 & 0.199 & 0.4799 & 0.7733 & 0.7692 \\
\hline 13 & 0.028 & 4.4 & 0.22 & 0.4829 & 0.5042 & 0.5 \\
\hline 14 & 0.0276 & 3.04 & 0.19 & 0.4789 & 0.746 & 1 \\
\hline 15 & 0.0208 & 2.32 & 0.19 & 0.4201 & 1 & 1 \\
\hline 16 & 0.0088 & 2.61 & 0.19 & 0.3452 & 0.8794 & 1 \\
\hline 17 & 0.0309 & 4.42 & 0.21 & 0.5138 & 0.5018 & 0.6 \\
\hline 18 & 0.0141 & 3.3 & 0.21 & 0.3747 & 0.6834 & 0.6 \\
\hline 19 & 0.0529 & 6.55 & 0.24 & 1 & 0.3333 & 0.375 \\
\hline 20 & 0.0201 & 4.35 & 0.205 & 0.4148 & 0.5103 & 0.6667 \\
\hline 21 & 0.0304 & 4.38 & 0.2 & 0.5082 & 0.5066 & 0.75 \\
\hline 22 & 0.0073 & 2.78 & 0.195 & 0.3377 & 0.8214 & 0.8571 \\
\hline 23 & 0.0283 & 6.38 & 0.225 & 0.4859 & 0.3425 & 0.4615 \\
\hline 24 & 0.0101 & 5.9 & 0.24 & 0.352 & 0.3714 & 0.375 \\
\hline 25 & 0.0278 & 3.27 & 0.19 & 0.4809 & 0.69 & 1 \\
\hline 26 & 0.0064 & 4.21 & 0.22 & 0.3333 & 0.5281 & 0.5 \\
\hline
\end{tabular}


Table 5 Grey relation grade

\begin{tabular}{|c|c|c|c|c|c|}
\hline Experiment no. & $A\left(T_{\text {on }}\right)$ & $B\left(T_{\text {off }}\right)$ & $C$ (IP) & $D\left(W_{\mathrm{f}}\right)$ & GRG \\
\hline 1 & 40 & 15 & 3 & 30 & 0.5523 \\
\hline 2 & 30 & 10 & 3 & 40 & 0.5048 \\
\hline 3 & 40 & 15 & 3 & 50 & 0.5024 \\
\hline 4 & 40 & 10 & 2 & 40 & 0.4545 \\
\hline 5 & 20 & 5 & 3 & 50 & 0.522 \\
\hline 6 & 30 & 10 & 2 & 50 & 0.5822 \\
\hline 7 & 40 & 15 & 1 & 30 & 0.452 \\
\hline 8 & 30 & 10 & 2 & 30 & 0.5227 \\
\hline 9 & 30 & 5 & 2 & 40 & 0.4432 \\
\hline 10 & 40 & 5 & 1 & 50 & 0.4089 \\
\hline 11 & 20 & 5 & 1 & 50 & 0.6459 \\
\hline 12 & 20 & 15 & 3 & 30 & 0.6741 \\
\hline 13 & 20 & 5 & 3 & 30 & 0.4957 \\
\hline 14 & 20 & 10 & 2 & 40 & 0.7416 \\
\hline 15 & 20 & 15 & 3 & 50 & 0.8067 \\
\hline 16 & 20 & 15 & 1 & 50 & 0.7415 \\
\hline 17 & 30 & 10 & 2 & 40 & 0.5385 \\
\hline 18 & 40 & 15 & 1 & 50 & 0.5527 \\
\hline 19 & 40 & 5 & 3 & 30 & 0.5694 \\
\hline 20 & 30 & 10 & 1 & 40 & 0.5306 \\
\hline 21 & 30 & 10 & 2 & 40 & 0.5883 \\
\hline 22 & 20 & 15 & 1 & 30 & 0.6721 \\
\hline 23 & 40 & 5 & 3 & 50 & 0.43 \\
\hline 24 & 40 & 5 & 1 & 30 & 0.3661 \\
\hline 25 & 30 & 15 & 2 & 40 & 0.7236 \\
\hline 26 & 20 & 5 & 1 & 30 & 0.4538 \\
\hline
\end{tabular}

\section{Grey relation grade}

The Grey relational grade $\left(\Gamma_{i}\right)$ is calculated by averaging the Grey relational coefficients:

$\Delta_{i}=\frac{1}{Q} \sum_{k=1}^{Q} \epsilon_{i}(k)$ where $Q$ is the total number of responses. A high Grey relational grade corresponds to intense relational degree between the given sequence and the reference sequence. The reference sequence, $y_{0}^{*}(k)$, represents the best process sequence; therefore, higher Grey relational grade means that the corresponding parameter combination is closer to the optimal setting (Table 5).

\section{Multi-response optimisation by Grey analysis}

The following Table 4 shows the experimental number along with the result of MRR, SR, and Kerf width. Grey relation coefficient for the three responses $M R R \in_{i}(1)$, $S R \in_{i}(2)$, and Kerf width $\in_{\mathrm{i}}(3)$ has been calculated and shown in the Table 4 corresponding to MRR, SR, and Kerf Width using Eqs. 1, 2 and 3.

From Eq. 4, the three-response is converted into single response, i.e. Grey relation grade. It has been calculated, corresponding to parameter $T_{\text {on }}, T_{\text {off }}$, current and wire feed by passing the response MRR, SR and Kerf width.

The purpose of distinguishing coefficient is to expand or compress the range of the Grey relational coefficient. The distinguishing coefficient can be selected by decision maker judgement, and different distinguishing coefficients usually provide different results in GRA. They led to the same optimum factor levels. In this case distinguishing coefficient is taken as 0.5. Figure 2 shows that Grey relation grade should be found near 0.8 (Table 5).

In Table 6, it is shown that $P$ value of model is linear and less than 0.05 , so these terms are significant, square and 2-way interaction $P$ value is more than 0.05 so these terms are non-significant, and non-significance lack of fit is desired in this case value of LOF that is 0.419 which is more than 0.05 and non-significant. The coefficient of determination $\left(R^{2}\right)$ which indicates the percentage of total variation in the response explained by the terms in the model is $87.96 \%$ (Fig. 4).
Table 6 ANOVA analysis for Grey relation grade

\begin{tabular}{lrllrll}
\hline Source & DF & \multicolumn{6}{l}{ Grey relation grade } \\
\cline { 3 - 7 } & & Adj SS & Adj MS & $F$-value & $P$ value & \% contribution \\
\hline Model & 14 & 0.28801 & 0.020572 & 5.74 & 0.003 & 87.95917 \\
Linear & 4 & 0.23287 & 0.058218 & 16.24 & 0 & 71.11924 \\
Square & 4 & 0.008239 & 0.00206 & 0.57 & 0.687 & 2.516217 \\
2-Way interaction & 6 & 0.046901 & 0.007817 & 2.18 & 0.124 & 14.32372 \\
Error & 11 & 0.039426 & 0.003584 & & & 12.04083 \\
Lack-of-fit (LOF) & 10 & 0.038186 & 0.003819 & 3.08 & 0.419 & 11.66213 \\
Pure error & 1 & 0.00124 & 0.00124 & & & 0.3787 \\
Total & 25 & 0.327436 & & & & 100 \\
\hline
\end{tabular}


Fig. 4 Grey relation grade variation with number of experiment

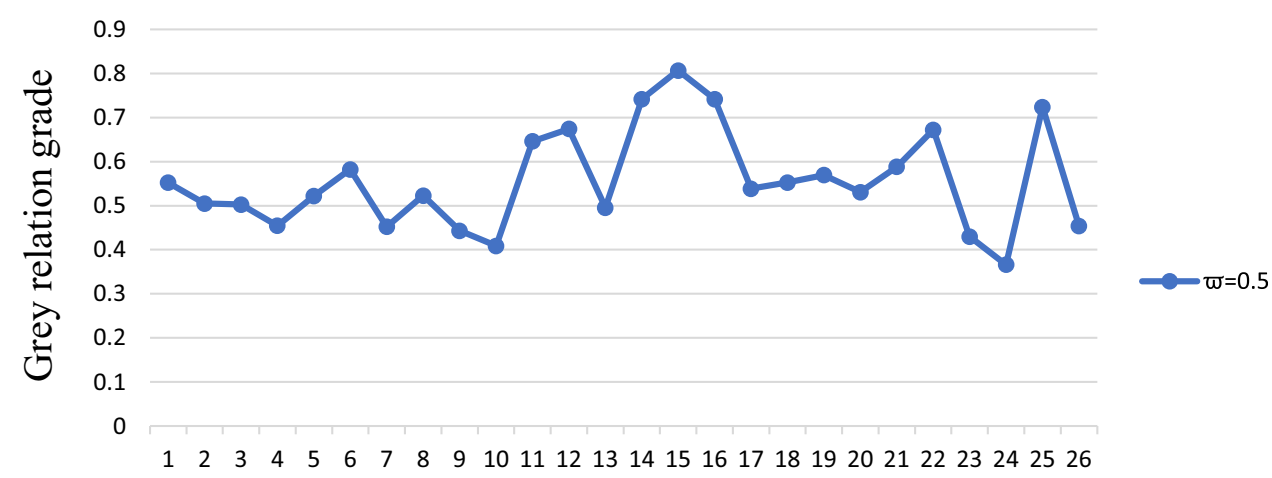

Experiment number

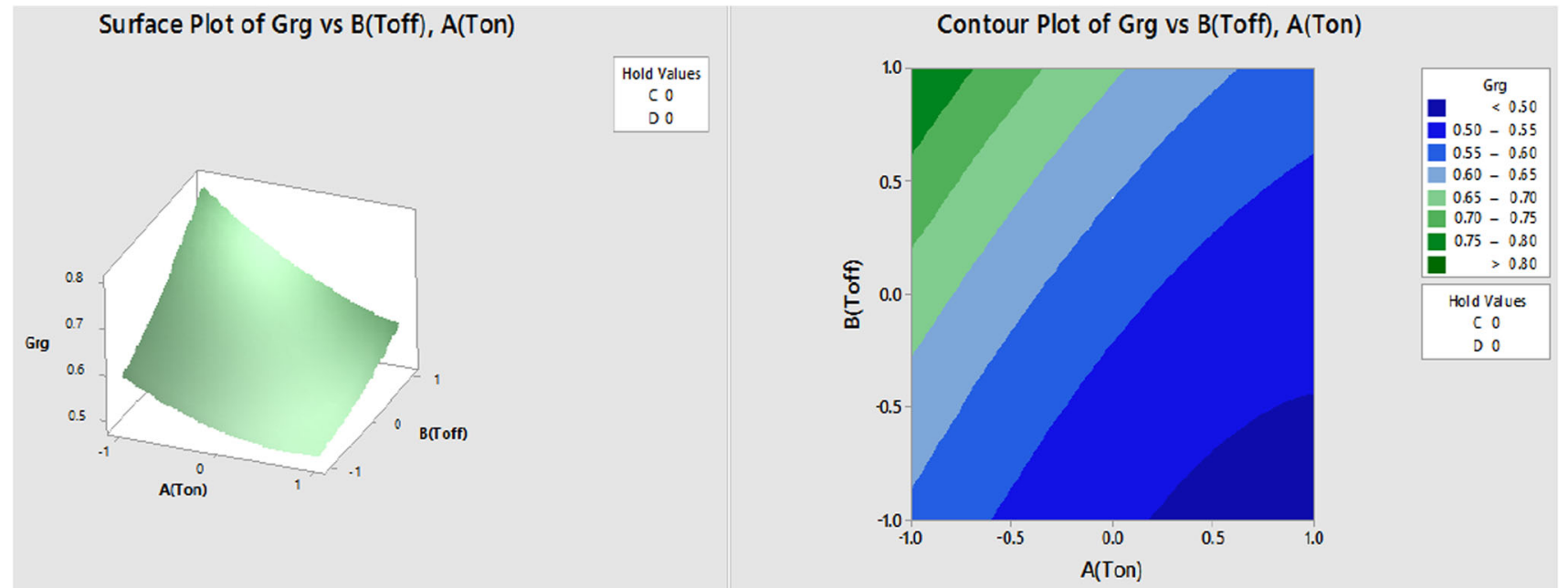

Fig. 5 Surface and Contour plot of GRG versus $A\left(T_{\text {on }}\right), B\left(T_{\text {off }}\right)$

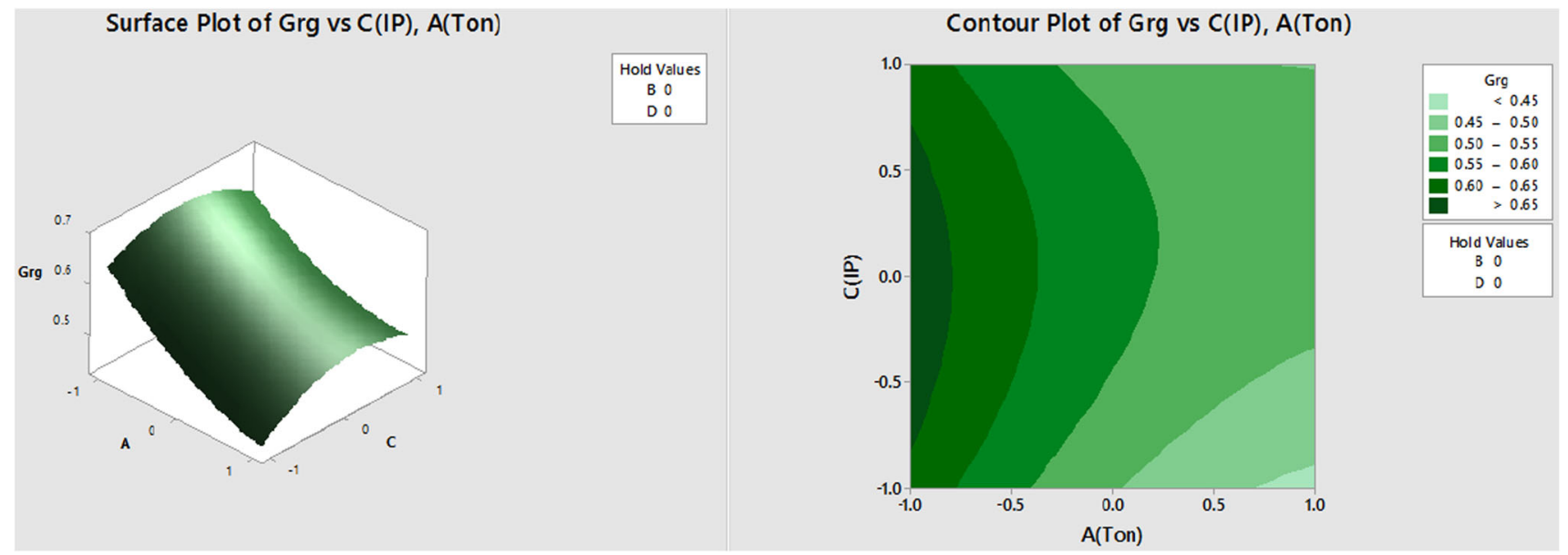

Fig. 6 Surface and Contour plot of GRG versus $A\left(T_{\mathrm{on}}\right), C$ (IP) 


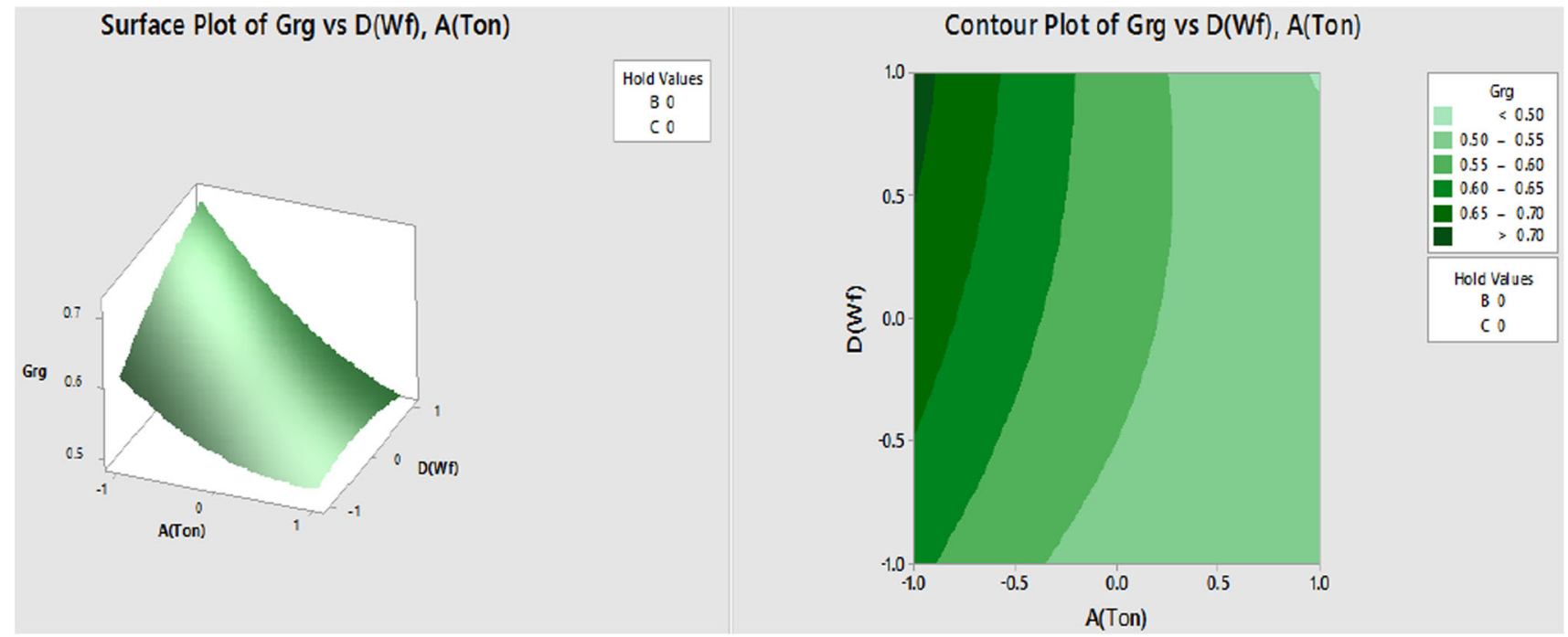

Fig. 7 Surface and Contour plot of GRG versus $A\left(T_{\mathrm{on}}\right), D\left(W_{\mathrm{f}}\right)$

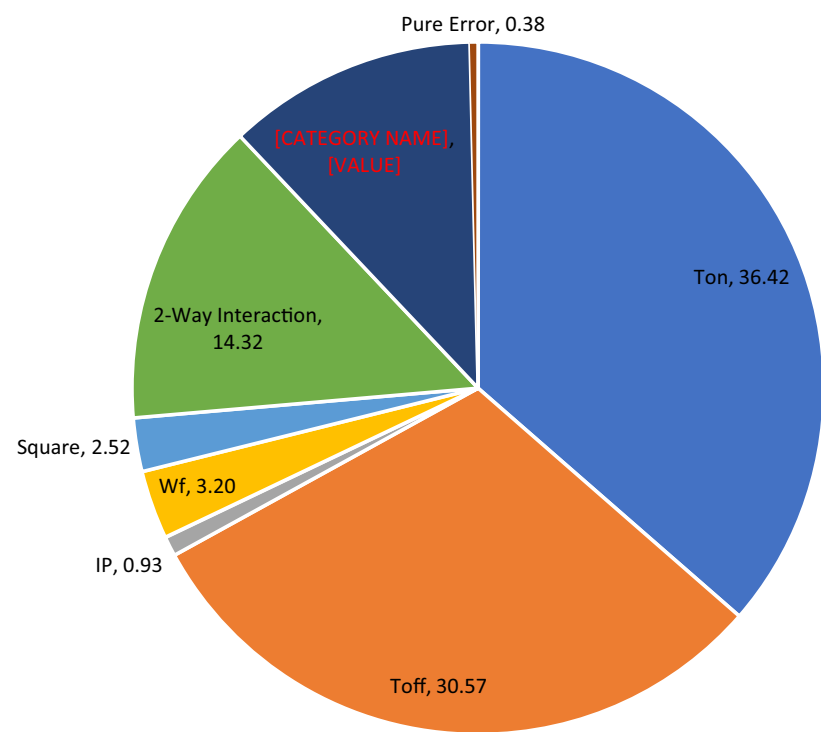

Fig. 8 Percentage contribution of factors on the Grey relation grade

$$
\begin{aligned}
\mathrm{GRG}= & 0.5654-0.0814 A+0.0746 B+0.0130 C \\
& +0.0241 D(\text { coded form })
\end{aligned}
$$

In Fig. 5, it is observed that GRG is maximum at a lower value of $T_{\text {on }}$ and a high value of $T_{\text {off }}$.

It is noticed from the Fig. 6 response surface plot that GRG is maximum at middle value of current and a higher value of $T_{\text {on }}$.

From Fig. 7, it is clearly noticed that GRG is maximum at lower value of $T_{\text {on }}$ and at higher value of $D\left(W_{\mathrm{f}}\right)$.

ANOVA is applied to get the percentage of contribution of different parameter and their interactions. The percentage contribution is calculated by sum of each square parameter with total sum of square. The lack of fit is $11.66 \%$ while pure error is $0.38 \%$ (Fig. 8).
Table 7 Optimised process parameters of WEDM by Grey analysis

\begin{tabular}{lcl}
\hline Parameter & Value & Units \\
\hline$T_{\text {on }}$ & 20 & $\mu \mathrm{s}$ \\
$T_{\text {off }}$ & 15 & $\mu \mathrm{s}$ \\
IP & 2 & $\mathrm{~A}$ \\
Wire feed & 50 & $\mathrm{~mm} / \mathrm{s}$ \\
\hline
\end{tabular}

\section{Response optimisation of GRG and optimal parameter setting}

With the help of response optimizer, we have found the optimal parameter setting for all three responses:

\begin{tabular}{lllllll}
\hline Response & Goal & Lower & Target & Upper & Weight & Importance \\
\hline GRG & Maximum & 0.3661 & 1 & 1 & 1 & 1 \\
\hline
\end{tabular}

Predicted GRG responses $=0.855339$

Desirability $=0.771792$

For the above predicted response, the optimal parameter setting obtained is shown in Table 7.

\section{Conclusion}

In this paper, the performance parameters namely metal removal rate, surface roughness and kerf width are investigated by varying the machining parameters on workpiece HSS M2 grade steel. Molybdenum wire of $0.18 \mathrm{~mm}$ diameter is used as an electrode in WEDM. The performance parameters of pulse-on time $\left(T_{\mathrm{on}}\right)$, pulse-off time $\left(T_{\text {off }}\right)$, peak current (IP) and wire feed rate $\left(W_{\mathrm{f}}\right)$ are analysed. FCCD based on RSM is used for experimental 
design. Using Grey analysis, WEDM's parameter was optimised and found that optimal responses were material removal rate $(0.03137 \mathrm{~g} / \mathrm{min})$, surface roughness $(1.79 \mu \mathrm{m})$ and Kerf width $(0.19 \mathrm{~mm})$ at optimal parameter at pulse-on time $20 \mu$ s, pulse-off time $15 \mu$ s current $2 \mathrm{~A}$, and wire feed $50 \mathrm{~mm} / \mathrm{s}$ which are the best parametric combination.

Open Access This article is distributed under the terms of the Creative Commons Attribution 4.0 International License (http://creative commons.org/licenses/by/4.0/), which permits unrestricted use, distribution, and reproduction in any medium, provided you give appropriate credit to the original author(s) and the source, provide a link to the Creative Commons license, and indicate if changes were made.

\section{References}

Baig K, Venkaiah N (2001) Parametric optimization of WEDM for Hastelloy C276 using GRA method. Int J Eng Dev Res 1(2):1-7

Deng J (1982) Control problems of grey systems. Syst Control Lett 1(5):288-294

Huang JT, Liao YS (2003) Optimization of machining parameters of Wire-EDM based on Grey relational and statistical analyses. Int J Prod Res 41(8):1707-1720. https://doi.org/10.1080/ 1352816031000074973

Jaganathan P, Kumar N, Sivasubramanian R (2012) Optimization of WEDM parameters using Taguchi method. Int J Sci Res Publ 2(12):1-4

Kumar K, Kumar RR (2013) Modelling and optimization of WEDM. Int J Mod Eng Res 3(3):1645-1648

Lal S, Kumar S, Khan ZA, Siddiquee AN (2015) Multi-response optimization of wire electrical discharge machining process parameters for A17075/A12O3/SiC hybrid composite using Taguchi-based Grey relational analysis. J Eng Manuf 229(2):229-237. https://doi.org/10.1177/0954405414526382
Mahapatra SS, Patnaik A (2007) Int J Adv Manuf Technol 34:911. https://doi.org/10.1007/s00170-006-0672-6

Majhi SK, Pradhan MK, Soni H (2013) Application of integrated RSM-Grey-entropy analysis for optimization of EDM parameters. In: Proceedings of the International Conference on Advanced Research in Mechanical Engineering, Coimbatore, ISBN: 978-93-83060-03-0

Nayak BB, Mahapatra SS (2016) Optimization of WEDM process parameters using deep cryo-treated Inconel 718 as work material. Int J Eng Sci Technol 19:161-170

Pasam VK, Battula SB, Valli MP, Swapna M (2010) Optimizing surface finish in WEDM using the Taguchi parameter design method. J Braz Soc Mech Sci Eng 49(2010):155-166

Pradhan MK (2013) Estimating the effect of process parameters on surface integrity of EDM AISI D2 tool steel by response surface methodology coupled with Grey relation analysis. Int $\mathbf{J}$ Adv Manuf Technol 67:2051-2062

Saha A, Mondal SC (2016) Multi-objective optimization in WEDM process of nanostructured hard facing materials through hybrid techniques. Measurement 94:46-59

Shivade AS, Shinde VD (2014) Multi-objective optimization in WEDM of D3 tool steel using integrated approach of Taguchi method \& Grey relational analysis. J Ind Eng Int 10:149. https:// doi.org/10.1007/s40092-014-0081-7

Singha V, Pradhan SK (2014) Optimization of WEDM parameters using Taguchi technique and response surface methodology in machining of AISI D2 steel. Procedia Eng 97:1597-1608. https://doi.org/10.1016/j.proeng.2014.12.310

Sinha P, Kumar R, Singh GK, Thomas D, Srivastava T (2015) Optimization of wire EDM of AISI D3 tool steel using orthogonal array with principal component analysis. Mater Today Proc 2(4-5):2512-2521. https://doi.org/10.1016/j.matpr. 2015.07.196

Varun A, Venkaiah N (2014) Simultaneous optimization of WEDM responses using Grey relational analysis coupled with genetic algorithm while machining EN 353. Int J Adv Manuf Technol. https://doi.org/10.1007/s00170-014-6198-4 